Journal of Physical Activity and Sports, 1 (1), 2020, 110-123

\title{
Pengaruh Penggunaan Google Classroom dan Zoom Meeting Dalam Pembelajaran Pendidikan Jasmani Daring Terhadap Minat Belajar Siswa Kelas xi di SMK Wisudha Karya Kudus
}

\author{
Andre Febriansyah Putra Nugraha \\ Universitas PGRI Semarang, Jalan Sidodadi Timur Nomor 24-Dr.Cipto, Karangtempel, Semarang Timur, Kota \\ Semarang, Jawa Tengah, 50232, Indonesia. \\ * Coressponding Author. E-mail: nugasastra@gmail.com
}

\begin{abstract}
Andre Febriansyah Putra Nugraha, "The effect of using google classrooms and zoom meetings in online physical education learning on learning interest of class XI students at SMK Wisudha Karya Kudus", Health and Recreation Physical Education Study Program, Faculty of Social Sciences and Sports Education, PGRI University Semarang, 2020. The background of this study is the results of the daily test scores of physical education subjects for class XI students at SMK Wisudha Karya Kudus, there are two XI classes who get daily test scores below the minimum completeness criteria of 75, namely XI TITL 1 and XI TITL 2. The formulation of the research problem is which is better between the use of google classroom and zoom meeting in online physical education learning to increase student interest in class XI at SMK Wisudha Karya Kudus. The purpose of this study was to determine the comparison of the use of google classroom and zoom meeting in online physical education learning on the learning interest of class XI students at SMK Wisudha Karya Kudus.

This research method uses quantitative research methods. This type of research used in this study is a quasi experimental design (quasi-experimental). In this study using a two group research design pre-test post-test design with purposive sampling technique. The use of google classroom learning media in online Physical Education lessons can increase the learning interest of class XI TITL 1 students an increase in learning interest by $14.26 \%$, while in class XI TITL 2 students there is an increase in learning interest by $6.49 \%$. While the use of zoom meeting learning media in online physical education lessons can increase student interest in learning class XI TITL 1 , there is an increase in learning interest by $1.02 \%$, while in class XI TITL 2 students there is an increase in interest in learning by $1.27 \%$. The conclusion is that the increase in the results of interest in learning when using google classroom learning media is higher than the zoom meeting. Hopefully it will be able to increase student interest in learning and be useful for student motivation in learning physical education online during the Covid-19 pandemic.
\end{abstract}

Keywords: Google Classroom, Zoom Meeting, Student Interests.

\begin{abstract}
ABSTRAK
Andre Febriansyah Putra Nugraha, "Pengaruh penggunaan google classroom dan zoom meeting dalam pembelajaran pendidikan jasmani daring terhadap minat belajar siswa kelas XI di SMK Wisudha Karya Kudus", Program Studi Pendidikan Jasmani Kesehatan dan Rekreasi, Fakultas Pendidikan Ilmu Pengetahuan Sosial dan Keolahragaan, Universitas PGRI Semarang, 2020. Latar belakang dari penelitian ini adalah hasil ulangan harian nilai mata pelajaran penjas siswa kelas XI di SMK Wisudha Karya Kudus ada dua kelas XI yang mendapatkan nilai ulangan harian dibawah kriteria ketuntasan minimal 75, yaitu XI TITL 1 dan XI TITL 2. Rumusan masalah penelitian ini yaitu manakah yang lebih baik antara penggunaan google classroom dan zoom meeting dalam pembelajaran penjas daring untuk meningkatkan minat belajar siswa kelas XI di SMK Wisudha Karya Kudus. Tujuan penelitian ini yaitu untuk mengetahui perbandingan penggunaan google classroom dan zoom meeting dalam pembelajaran penjas daring terhadap minat belajar siswa kelas XI di SMK Wisudha Karya Kudus. Metode penelitian ini menggunakan metode penelitian kuantitatif. Jenis penelitian yang digunakan pada penelitian ini adalah quasi eksperimental design (eksperimen semu). Pada penelitian ini menggunakan desain penelitian two group pre-test post-test design dengan teknik sampling purposive. Penggunaan media pembelajaran google classroom pada pelajaran penjas secara daring dapat meningkatkan minat belajar siswa
\end{abstract}


Andre Febriansyah Putra Nugraha

kelas XI TITL 1 terjadi peningkatan minat belajar sebesar 14,26\%, sedangkan pada siswa kelas XI TITL 2 terjadi peningkatan minat belajar sebesar $6,49 \%$. Sedangkan penggunaan media pembelajaran zoom meeting pada pelajaran penjas secara daring dapat meningkatkan minat belajar siswa kelas XI TITL 1 terjadi peningkatan minat belajar sebesar 1,02\%, sedangkan pada siswa kelas XI TITL 2 terjadi peningkatan minat belajar sebesar $1,27 \%$. Kesimpulannya adalah bahwa peningkatan hasil minat belajar saat menggunakan media pembelajaran google classroom lebih tinggi daripada zoom Meeting. Semoga mampu meningkatkan minat belajar siswa dan bermanfaat untuk motivasi belajar siswa dalam pembelajaran penjas daring selama pandemi Covid-19.

Kata Kunci: Google Classroom, Zoom Meeting, Minat Siswa.

\section{PENDAHULUAN}

Kriteria ketuntasan minimal mata pelajaran penjas di sekolah ini adalah 75. Namun setelah guru memberikan ulangan harian melalui WhattAps kepada siswa di tengah Pandemi Corona Virus Disease-19 (Covid-19), berdasarkan hasil ulangan harian nilai mata pelajaran penjas siswa kelas XI di SMK Wisudha Karya Kudus ada dua kelas XI yang mendapatkan nilai ulangan harian dibawah KKM. Kelas XI Teknik Instalasi Tenaga Listrik 1 jumlah siswa 35, dengan hasil 29 orang mendapatkan hasil ulang harian $<75 \mathrm{KKM}$ dan 6 orang mendaptkan hasil ulangan harian $>75$ KKM. Sedangkan Kelas XI Teknik Instalasi Tenaga Listrik 2 jumlah siswa 34, dengan hasil 16 orang mendapatkan hasil ulang harian $<75 \mathrm{KKM}$ dan 18 orang mendaptkan hasil ulangan harian $>75 \mathrm{KKM}$.

Kelas XI adalah kelas yang memiliki nilai dibawah rata-rata dan di kelas ini karakter dari tiap individu sudah terbentuk. Di kelas XI ini peneliti akan lebih mudah menerapkan aplikasi pembelajaran penjas daring dikarenakan mereka lebih mudah dikendalikan, lebih mudah memahami tiap individu satu sama lain dan mulai mampu menilai karakter guru mereka. Apa bila guru menerapkan aplikasi pembelajaran penjas daring yang menarik maka akan muncul di pikiran siswa bahwa pembelajaran penjas itu lebih menarik dari yang biasanya mereka lakukan.

\section{METODE}

Metode penelitian kuantitatif menurut Sugiyono, (2017: 8) dapat diartikan sebagai metode penelitian yang berdasarkan pada filsafat positivisme, digunakan untuk meneliti pada populasi atau sampel tertentu, pengumpulan data menggunakan instrumen penelitian, analisis data bersifat kuantitatif statistik, dengan tujuan untuk menguji hipotesis yang telah ditetapkan. Jenis penelitian yang digunakan pada penelitian ini adalah Quasi Eksperimental Design (Eksperimen Semu). Menurut Sugiyono, (2017: 114) desain ini mempunyai kelompok kontrol, tetapi tidak dapat berfungsi sepenuhnya untuk mengontrol variabel-variabel luar yang mempengaruhi pelaksanaan eksperimen. Metode ini digunakan untuk pengaruh penggunaan Google Classroom dan Zoom Meeting dalam pembelajaran penjas daring teradap minat belajar siswa kelas XI SMK Wisudha Karya Kudus. Sedangkan untuk penelitian ini menggunakan desain penelitian Two Group Pre-Test Post-Test 
Design. Menurut Arikunto, (2013: 124) Two Group Pre-Test Post-Test Design . Populasi Berdasarkan pendapat tersebut maka populasi pada penelitian ini adalah kelas XI dengan 16 kelas yang berjumlah 559 siswa di SMK Wisudha Karya Kudus. Sampel Penelitian ini menggunakan teknik sampling purposive. Menurut Sugiyono, (2017: 124) sampling purposive adalah teknik penentuan sampel dengan pertimbangan tertentu. Kriteria yang di nilai untuk mendapatkan sampel adalah kelas yang memiliki jam pelajaran penjas di jam ke 3-4, serta kelas dengan nilai ulangan harian terendah. Maka sampel yang didapat dalam penelitian ini adalah siswa kelas XI Teknik Instalasi Tenaga Listrik 1 jumlah 35 siswa dan XI Teknik Instalasi Tenaga Listrik 2 jumlah 34 siswa, jadi total sampel ada 69 siswa di SMK Wisudha, Teknik Pengumpulan Data Pada penelitian ini pengumpulan data yang digunakan

\section{HASIL DAN PEMBAHASAN}

1. Uji Prasyarat Analisis

Sebelum analisis uji hipotesis untuk menjawab tujuan penelitian yaitu pengaruh penggunaan Google Classroom dan Zoom Meeting dalam pembelajaran penjas daring terhadap minat belajar siswa Kelas XI di SMK Wisudha Karya Kudus. Maka perlu adanya uji prasyarat analisis yang harus terpenuhi yaitu uji normalitas dan uji homogenitas.

a. Uji Normalitas

Uji normalitas data pre-test dan post-test hasil minat belajar kelas XI TITL 1 dan kelas XI TITL 2 yang menggunakan media pembelajaran Google Classroom sebagai berikut:

Tabel Hasil Uji Normalitas Minat Belajar dengan Google Classroom

\begin{tabular}{|c|c|c|c|c|}
\hline \multirow{2}{*}{ Kelas } & $\begin{array}{c}\text { Minat } \\
\text { Belajar }\end{array}$ & $\begin{array}{c}\text { Kolmogorov } \\
\text { Smirnov-Z }\end{array}$ & $\begin{array}{c}\text { Asymp.Sig. } \\
\text { (2-tailed) }\end{array}$ & Keterangan \\
\hline \multirow{2}{*}{ XI TITL 1 } & Pre-test & 1,273 & 0,078 & Normal \\
\cline { 2 - 5 } & Post-test & 0,947 & 0,331 & Normal \\
\hline \multirow{2}{*}{ XI TITL 2 } & Pre-test & 1,109 & 0,171 & Normal \\
\cline { 2 - 5 } & Post-test & 0,698 & 0,714 & Normal \\
\hline
\end{tabular}

Sumber : Data primer penelitian yang diolah (2020)

Hasil uji normalitas dengan Kolmogorov Smirnov Test pada Tabel 5, untuk data pre-test minat belajar kelas XI TITL 1 diperoleh nilai Asymp.Sig.(2-tailed) sebesar 0,078, data post-test minat belajar kelas XI TITL 1 diperoleh nilai Asymp.Sig.(2-tailed) sebesar 0,331, data pre-test minat belajar kelas XI TITL 2 diperoleh nilai Asymp.Sig.(2-tailed) sebesar 0,171, data pre-test minat belajar kelas XI TITL 2 diperoleh 0,714. Karena semua data pre-test dan post-test minat belajar dengan menggunakan media pembelajaran Google Classroom memiliki nilai Asymp.Sig $>\alpha$ $(0,05)$ yang berarti data berdistribusi normal (uji normalitas terpenuhi). 
Pengaruh Penggunaan Google Classroom dan Zoom Meeting dalam Pembelajaran Pendidikan Jasmani Daring

Terhadap Minat Belajar Siswa XI di SMK Wisudha Karya Kudus

Andre Febriansyah Putra Nugraha

Uji normalitas data pre-test dan post-test hasil minat belajar kelas XI TITL 1 dan kelas XI TITL 2 yang menggunakan media pembelajaran Zoom Meeting sebagai berikut:

Tabel Hasil Uji Normalitas Minat Belajar dengan Zoom Meeting

\begin{tabular}{|c|c|c|c|c|}
\hline \multirow{2}{*}{ Kelas } & $\begin{array}{c}\text { Minat } \\
\text { Belajar }\end{array}$ & $\begin{array}{c}\text { Kolmogorov } \\
\text { Smirnov-Z }\end{array}$ & $\begin{array}{c}\text { Asymp.Sig. } \\
\text { (2-tailed) }\end{array}$ & Keterangan \\
\hline \multirow{2}{*}{ XI TITL 1 } & Pre-test & 1,355 & 0,051 & Normal \\
\cline { 2 - 5 } & Post-test & 0,993 & 0,278 & Normal \\
\hline \multirow{2}{*}{ XI TITL 2 } & Pre-test & 1,000 & 0,270 & Normal \\
\cline { 2 - 5 } & Post-test & 1,323 & 0,060 & Normal \\
\hline
\end{tabular}

Sumber : Data primer penelitian yang diolah (2020)

Hasil uji normalitas dengan Kolmogorov Smirnov Test pada Tabel 6, untuk data pre-test minat belajar kelas XI TITL 1 diperoleh nilai Asymp.Sig.(2-tailed) sebesar 0,051, data post-test minat belajar kelas XI TITL 1 diperoleh nilai Asymp.Sig.(2-tailed) sebesar 0,278, data pre-test minat belajar kelas XI TITL 2 diperoleh nilai Asymp.Sig.(2-tailed) sebesar 0,270, data pre-test minat belajar kelas XI TITL 2 diperoleh 0,060. Karena semua data pre-test dan post-test minat belajar dengan menggunakan media pembelajaran Zoom Meeting memiliki nilai Asymp.Sig $>\alpha(0,05)$ yang berarti data berdistribusi normal (uji normalitas terpenuhi).

b. Uji Homogenitas

Tabel . Hasil Uji Homogenitas Minat Belajar dengan Google Classroom

\begin{tabular}{|c|c|c|c|c|}
\hline Minat Belajar & Kelas & Levene Statistic & Sig. & Keterangan \\
\hline \multirow{2}{*}{ Pre-test } & XI TITL 1 & \multirow{2}{*}{1,254} & \multirow{2}{*}{0,267} & \multirow{2}{*}{ Homogen } \\
\hline & XI TITL 2 & & & \\
\hline \multirow{2}{*}{ Post-test } & XI TITL 1 & \multirow{2}{*}{0,687} & \multirow{2}{*}{0,410} & \multirow{2}{*}{ Homogen } \\
\hline & XI TITL 2 & & & \\
\hline
\end{tabular}

Sumber : Data primer penelitian yang diolah (2020)

Berdasarkan hasil uji homogenitas pada Tabel 7, diperoleh hasil uji homogenitas untuk data pre-test (sebelum diberikan media pembelajaran Google Classroom) antara kelas XI TITL 1 dan kelas XI TITL 2 dengan nilai Sig. sebesar 0,267. Sedangkan hasil uji uji homogenitas untuk data post-test (setelah diberikan media pembelajaran Google Classroom) antara kelas XI TITL 1 dan kelas XI TITL 2 dengan nilai Sig. sebesar 0,410. Karena diperoleh nilai Sig. $>\alpha(0,05)$. Maka $\mathrm{H}_{0}$ diterima dan $\mathrm{H}_{\mathrm{a}}$ ditolak yang berarti data pre-test (sebelum diberikan media pembelajaran Google Classroom) dan data post-test (setelah diberika media pembelajaran Google Classroom) antara kelas XI TITL 1 dan kelas XI TITL 2 memiliki varians yang homogen/sama (uji homogenitas terpenuhi).

Uji homogenitas untuk menguji varians antara minat belajar siswa kelas XI TITL 1 dan kelas XI TITL 2 dengan menggunakan media pembelajaran Zoom Meeting sebagai berikut: 
Tabel 4. 8. Hasil Uji Homogenitas Minat Belajar dengan Zoom Meeting

\begin{tabular}{|c|c|c|c|c|}
\hline Minat Belajar & Kelas & Levene Statistic & Sig. & Keterangan \\
\hline \multirow{2}{*}{ Pre-test } & XI TITL 1 & \multirow{2}{*}{0,044} & \multirow[b]{2}{*}{0,834} & \multirow[b]{2}{*}{ Homogen } \\
\hline & XI TITL 2 & & & \\
\hline \multirow[b]{2}{*}{ Post-test } & XI TITL 1 & \multirow{2}{*}{1,489} & \multirow{2}{*}{0,227} & \multirow[b]{2}{*}{ Homogen } \\
\hline & XI TITL 2 & & & \\
\hline
\end{tabular}

Sumber : Data primer penelitian yang diolah (2020)

Berdasarkan hasil uji homogenitas pada Tabel 8, diperoleh hasil uji homogenitas untuk data pre-test (sebelum diberikan media pembelajaran Zoom Meeting) antara kelas XI TITL 1 dan kelas XI TITL 2 dengan nilai Sig. sebesar 0,834. Sedangkan hasil uji uji homogenitas untuk data posttest (setelah diberikan media pembelajaran Zoom Meeting) antara kelas XI TITL 1 dan kelas XI TITL 2 dengan nilai Sig. sebesar 0,227. Karena diperoleh nilai Sig. $>\alpha(0,05)$. Maka $\mathrm{H}_{0}$ diterima dan $\mathrm{H}_{\mathrm{a}}$ ditolak yang berarti data pre-test (sebelum diberikan media pembelajaran Zoom Meeting) dan data post-test (setelah diberika media pembelajaran Zoom Meeting) antara kelas XI TITL 1 dan kelas XI TITL 2 memiliki varians yang homogen/sama (uji homogenitas terpenuhi).

2. Uji Hipotesis

a. Uji Hipotesis 1 ( Media Pembelajaran Google Classroom)

Uji hipotesis ini bertujuan untuk mengetahui pengaruh penggunaan google classroom dalam pembelajaran penjas daring terhadap minat belajar siswa kelas XI SMK Wisudha Karya Kudus. Uji hipotesis ini dilakukan pada data hasil minat belajar siswa kelas XI TITL 1 dan kelas XI TITL 2 yang diberikan media pembelajaran google classroom. Analisis data menggunakan metode Paired Sample T-Test sebagai berikut:

Tabel Hasil Uji Hipotesis Minat Belajar siswa kelas XI TITL 1 dengan Google Classroom

\begin{tabular}{|c|c|c|c|c|}
\hline Minat Belajar & Rata-Rata & Thitung & Ttabel $(\boldsymbol{\alpha}=\mathbf{5 \%}, \mathbf{d f}=\mathbf{3 4})$ & Sig. \\
\cline { 1 - 2 } Pre-test & 99,97 & \multirow{2}{*}{$-7,248$} & 2,032 & 0,000 \\
\hline Post-test & 114,23 & & & \\
\hline
\end{tabular}

Sumber : Data primer penelitian yang diolah (2020)

Berdasarkan hasil perhitungan pada Tabel 9, diperoleh hasil uji hipotesis minat belajar siswa kelas XI TITL1 dengan media pembelajaran google classroom dengan Thitung sebesar -7,248 dengan Ttabel $(2,032)$ dengan nilai signifikansi 0,000. Karena nilai $\mid$ Thitung $|=|-7,248 \mid>$ Ttabel $(2,032)$ dan Sig. $(0,000)<\alpha(0.05)$, maka $\mathrm{H}_{0}$ ditolak dan $\mathrm{H}_{\mathrm{a}}$ diterima yang berarti terdapat pengaruh penggunaan google classroom dalam pembelajaran penjas daring terhadap minat belajar siswa kelas XI SMK Wisudha Karya Kudus. Dimana terjadi peningkatan rata-rata minat belajar dari pre-test ke post-test yaitu 99,97 naik menjadi 114,23. 
Pengaruh Penggunaan Google Classroom dan Zoom Meeting dalam Pembelajaran Pendidikan Jasmani Daring

Terhadap Minat Belajar Siswa XI di SMK Wisudha Karya Kudus

Andre Febriansyah Putra Nugraha

Hasil uji hipotesis untuk hasil minat belajar dengan media pembelajaran google classroom pada siswa kelas XI TITL 2 sebagai berikut:

Tabel Hasil Uji Hipotesis Minat Belajar siswa kelas XI TITL 2

dengan Google Classroom

\begin{tabular}{|c|c|c|c|c|}
\hline Minat Belajar & Rata-Rata & Thitung & Ttabel $(\boldsymbol{\alpha}=\mathbf{5 \%}, \mathbf{d f}=\mathbf{3 3})$ & Sig. \\
\cline { 1 - 2 } Pre-test & 107,03 & \multirow{2}{*}{$-3,846$} & 2,035 & 0,001 \\
\hline Post-test & 113,97 & & & \\
\hline
\end{tabular}

Sumber : Data primer penelitian yang diolah (2020)

Berdasarkan hasil perhitungan pada Tabel 10, diperoleh hasil uji hipotesis minat belajar siswa kelas XI TITL 2 dengan media pembelajaran google classroom dengan Thitung sebesar -3,846 dengan Ttabel $(2,035)$ dengan nilai signifikansi 0,001. Karena nilai $\mid$ Thitung $|=|-3,846 \mid>$ Ttabel $(2,035)$ dan Sig. $(0,001)<\alpha(0.05)$, maka $\mathrm{H}_{0}$ ditolak dan $\mathrm{H}_{\mathrm{a}}$ diterima yang berarti Terdapat pengaruh penggunaan google classroom dalam pembelajaran pendidikan jasmani daring terhadap minat belajar siswa kelas XI SMK Wisudha Karya Kudus. Dimana terjadi peningkatan rata-rata minat belajar pre-test ke post-test yaitu 107,03 naik menjadi 113,97.

b. Uji Hipotesis 2 ( Media Pembelajaran Zoom Meeting)

Uji hipotesis ini bertujuan untuk mengetahui pengaruh penggunaan zoom meeting dalam pembelajaran pendidikan jasmani daring terhadap minat belajar siswa kelas XI SMK Wisudha Karya Kudus. Uji hipotesis ini dilakukan pada data hasil minat belajar siswa kelas XI TITL 1 dan kelas XI TITL 2 yang diberikan media pembelajaran zoom meeting. Analisis data menggunakan metode Paired Sample T-Test sebagai berikut:

Tabel Hasil Uji Hipotesis Minat Belajar siswa kelas XI TITL 1

dengan Zoom Meeting

\begin{tabular}{|c|c|c|c|c|}
\hline Minat Belajar & Rata-Rata & Thitung & Ttabel $(\boldsymbol{\alpha}=\mathbf{5 \%}, \mathbf{d f}=\mathbf{3 4})$ & Sig. \\
\cline { 1 - 2 } Pre-test & 111,71 & \multirow{2}{*}{$-2,038$} & 2,032 & 0,049 \\
\hline Post-test & 112,86 & & & \\
\hline
\end{tabular}

Sumber : Data primer penelitian yang diolah (2020)

Berdasarkan hasil perhitungan pada Tabel 11, diperoleh hasil uji hipotesis minat belajar siswa kelas XI TITL1 dengan media pembelajaran zoom meeting dengan Thitung sebesar -2,038 dengan Ttabel $(2,032)$ dengan nilai signifikansi 0,049. Karena nilai $\mid$ Thitung $|=|-2,038 \mid>$ Ttabel $(2,032)$ dan Sig. $(0,049)<\alpha(0.05)$, maka $\mathrm{H}_{0}$ ditolak dan $\mathrm{H}_{\mathrm{a}}$ diterima yang berarti terdapat pengaruh penggunaan zoom meeting dalam pembelajaran pendidikan jasmani daring terhadap minat belajar 
siswa kelas XI SMK Wisudha Karya Kudus. Dimana terjadi peningkatan rata-rata minat belajar dari pre-test ke post-test yaitu 111,71 naik menjadi 112,86.

Hasil uji hipotesis untuk hasil minat belajar dengan media pembelajaran zoom meeting pada siswa kelas XI TITL 2 sebagai berikut:

Tabel Hasil Uji Hipotesis Minat Belajar siswa kelas XI TITL 2 dengan Zoom Meeting

\begin{tabular}{|c|c|c|c|c|}
\hline Minat Belajar & Rata-Rata & Thitung & Ttabel $(\boldsymbol{\alpha}=\mathbf{5 \%}, \mathbf{d f}=\mathbf{3 3})$ & Sig. \\
\cline { 1 - 2 } Pre-test & 111,03 & \multirow{2}{*}{$-2,318$} & 2,035 & 0,027 \\
\hline Post-test & 112,44 & & & \\
\hline
\end{tabular}

Sumber : Data primer penelitian yang diolah (2020)

Berdasarkan hasil perhitungan pada Tabel 12, diperoleh hasil uji hipotesis minat belajar siswa kelas XI TITL 2 dengan media pembelajaran zoom meeting dengan Thitung sebesar -2,318 dengan Ttabel $(2,035)$ dengan nilai signifikansi 0,027. Karena nilai $\mid$ Thitung $|=|-2,318 \mid>$ Ttabel $(2,035)$ dan Sig. $(0,027)<\alpha(0.05)$, maka $\mathrm{H}_{0}$ ditolak dan $\mathrm{H}_{\mathrm{a}}$ diterima yang berarti Terdapat pengaruh penggunaan zoom meeting dalam pembelajaran pendidikan jasmani daring terhadap minat belajar siswa kelas XI SMK Wisudha Karya Kudus. Dimana terjadi peningkatan rata-rata minat belajar pretest ke posttest yaitu 111,03 naik menjadi 112,44.

c. Uji Hipotesis 2 ( Perbedaan Media Pembelajaran dengan Google Classroom dan Zoom Meeting)

Uji hipotesis ini bertujuan untuk mengetahui perbedaan pengaruh penggunaan google classroom dan zoom meeting dalam pembelajaran pendidikan jasmani daring terhadap minat belajar siswa kelas XI SMK Wisudha Karya Kudus. Penelitian ingin mengetahui penggunaan google classroom lebih baik dari penggunaan zoom meeting dalam pembelajaran pendidikan jasmani daring terhadap minat belajar siswa kelas XI SMK Wisudha Karya Kudus. uji hipotesis ini dilakukan pada data hasil minat belajar siswa kelas XI TITL 1 dan kelas XI TITL 2 yang diberikan media pembelajaran google classroom dengan zoom meeting. Analisis data menggunakan metode Independent Sample T-Test sebagai berikut:

Tabel Hasil Uji Hipotesis Perbedaan Minat Belajar dengan Google Classroom dan Zoom Meeting siswa kelas XI TITL 1

\begin{tabular}{|c|c|c|c|c|}
\hline Perlakuan & Rata-Rata & Thitung & Ttabel $(\boldsymbol{\alpha}=\mathbf{5 \%}, \mathbf{d f}=\mathbf{6 8})$ & Sig. \\
\cline { 1 - 2 } Google Classroom & 114,23 & \multirow{2}{*}{2,054} & 1,995 & 0,044 \\
\cline { 1 - 2 } Zoom Meeting & 112,86 & & & \\
\hline
\end{tabular}

Sumber : Data primer penelitian yang diolah (2020) 
Pengaruh Penggunaan Google Classroom dan Zoom Meeting dalam Pembelajaran Pendidikan Jasmani Daring

Terhadap Minat Belajar Siswa XI di SMK Wisudha Karya Kudus

Andre Febriansyah Putra Nugraha

Berdasarkan hasil perhitungan pada Tabel 13, diperoleh hasil uji hipotesis untuk perbedaan minat belajar dengan media pembelajaran Google Classroom dengan Zoom Meeting pada siswa kelas XI TITL1 dengan nilai Thitung sebesar 2,054, Ttabel $(\alpha=5 \%, \mathrm{df}=68)$ sebesar 1,995 dengan nilai Signifikansi 0,044. Karena nilai Thitung $(2,054)>$ Ttabel $(1,995)$ dan Sig. $(0,044)<\alpha(0,05)$. Maka $\mathrm{H}_{0}$ ditolak dan $\mathrm{H}_{\mathrm{a}}$ diterima yang berarti terdapat perbedaan pengaruh penggunaan google classroom dan zoom meeting dalam pembelajaran pendidikan jasmani daring terhadap minat belajar siswa kelas XI SMK Wisudha Karya Kudus. Dimana rata-rata hasil minat belajar siswa kelas XI TITL 1 saat menggunakan media pembelajaran google classroom sebesar 114,23 dan rata-rata hasil minat belajar siswa kelas XI TITL 1 saat menggunakan media pembelajaran zoom meeting sebesar 112,86. Karena rata-rata hasil minat belajar yang mengunakan media pembelajaran google classroom lebih tinggi daripada zoom meeting, maka dapat disimpulkan bahwa penggunaan google classroom lebih baik dari penggunaan zoom meeting dalam pembelajaran pendidikan jasmani daring terhadap minat belajar siswa kelas XI SMK Wisudha Karya Kudus.

Hasil uji hipotesis untuk perbedaan hasil minat belajar dengan media pembelajaran google classroom dan zoom meeting pada siswa kelas XI TITL 2 sebagai berikut

Tabel Hasil Uji Hipotesis Perbedaan Minat Belajar dengan Google Classroom dan Zoom Meeting siswa kelas XI TITL 2

\begin{tabular}{|c|c|c|c|c|}
\hline Perlakuan & Rata-Rata & Thitung & Ttabel $(\boldsymbol{\alpha}=\mathbf{5 \%} \mathbf{0 , d f = 6 6 )}$ & Sig. \\
\hline Google Classroom & 113,97 & 2,132 & 1,997 & 0,037 \\
\hline Zoom Meeting & 112,44 & & & \\
\hline
\end{tabular}

Sumber : Data primer penelitian yang diolah (2020)

Berdasarkan hasil perhitungan pada Tabel 14, diperoleh hasil uji hipotesis untuk perbedaan minat belajar dengan media pembelajaran Google Classroom dengan Zoom Meeting pada siswa kelas XI TITL1 dengan nilai Thitung sebesar 2,132, Ttabel $(\alpha=5 \%, \mathrm{df}=66)$ sebesar 1,997 dengan nilai Signifikansi 0,037. Karena nilai Thitung $(2,132)>$ Ttabel $(1,997)$ dan Sig. $(0,037)<\alpha(0,05)$. Maka $\mathrm{H}_{0}$ ditolak dan $\mathrm{H}_{\mathrm{a}}$ diterima yang berarti terdapat perbedaan pengaruh penggunaan google classroom dan zoom meeting dalam pembelajaran pendidikan jasmani daring terhadap minat belajar siswa kelas XI SMK Wisudha Karya Kudus. Dimana rata-rata hasil minat belajar siswa kelas XI TITL 2 saat menggunakan media pembelajaran google classroom sebesar 113,97 dan rata-rata hasil minat belajar siswa kelas XI TITL 2 saat menggunakan media pembelajaran zoom meeting sebesar 112,44. Karena rata-rata hasil minat belajar yang mengunakan media pembelajaran google classroom lebih tinggi daripada zoom meeting, maka dapat disimpulkan bahwa penggunaan google classroom lebih baik dari penggunaan zoom meeting dalam 
pembelajaran pendidikan jasmani daring terhadap minat belajar siswa kelas XI SMK Wisudha Karya Kudus.

Peningkatan hasil minat belajar siswa kelas XI TITL 1 dan XI TITL 2 SMK Wisudha Karya Kudus pada mata pelajaran penjas secara daring dengan menggunakan metode pembelajaran google classroom dan zoom meeting dapat dilihat pada Tabel 15 berikut ini:

Tabel Peningkatan Hasil Minat Belajar Siswa Kelas XI SMK Wisudha Karya Kudus

\begin{tabular}{|c|c|c|c|c|c|}
\hline Metode & Kelas & Data & Rata-Rata & Selisih & Persentase $(\%)$ \\
\hline \multirow{4}{*}{ Google Classroom } & \multirow{2}{*}{ Kelas XI TITL 1} & Pre-test & 99,971 & \multirow{2}{*}{14,258} & \multirow{2}{*}{$14,26 \%$} \\
\hline & & Post-test & 114,229 & & \\
\hline & \multirow{2}{*}{ Kelas XI TITL 2} & Pre-test & 107,029 & \multirow{2}{*}{6,942} & \multirow{2}{*}{$6,49 \%$} \\
\hline & & Post-test & 113,971 & & \\
\hline \multirow{4}{*}{ Zoom Meeting } & \multirow{2}{*}{ Kelas XI TITL 1} & Pre-test & 111,714 & \multirow{2}{*}{1,143} & \multirow{2}{*}{$1,02 \%$} \\
\hline & & Post-test & 112,857 & & \\
\hline & \multirow{2}{*}{ Kelas XI TITL 2} & Pre-test & 111,029 & \multirow{2}{*}{1,412} & \multirow{2}{*}{$1,27 \%$} \\
\hline & & Post-test & 112,441 & & \\
\hline
\end{tabular}

Sumber : Data primer penelitian yang diolah (2020)

Berdasarkan hasil perhitungan pada Tabel 15, penggunaan media pembelajaran Google Classroom pada pelajaran penjas secara daring dapat meningkatkan minat belajar siswa kelas XI SMK Wisudha Karya Kudus, dimana pada siswa kelas XI TITL 1 setelah diterapkan media pembelajaran google classroom terjadi peningkatan minat belajar sebesar $14,26 \%$, sedangkan pada siswa kelas XI TITL 2 setelah diterapkan media pembelajaran google classroom terjadi peningkatan minat belajar sebesar $6,49 \%$. Sedangkan penggunaan media pembelajaran Zoom meeting pada pelajaran penjas secara daring dapat meningkatkan minat belajar siswa kelas XI SMK Wisudha Karya Kudus, dimana pada siswa kelas XI TITL 1 setelah diterapkan media pembelajaran zoom meeting terjadi peningkatan minat belajar sebesar 1,02\%, sedangkan pada siswa kelas XI TITL 2 setelah diterapkan media pembelajaran zoom meeting terjadi peningkatan minat belajar sebesar 1,27\%. Karena peningkatan hasil minat belajar saat menggunakan media pembelajaran Google Classroom lebih tinggi daripada Zoom Meeting, maka penerapan media pembelajaran Google Classroom lebih efektif dalam meningkatkan minat belajar siswa dalam pelajaran penjas secara daring di SMK Wisudha Karya Kudus.

\section{PEMBAHASAN}

Pembelajaran secara daring merupakan salah satu alternatif yang digunakan oleh dunia pendidikan baik dari mulai jenjang SD, SMP dan SMA/SMK. Dimana pembelajaran daring menggunakan teknologi, informasi dan komunikasi . Salah satunya diterapkan pada SMK Wisudha Karya Kudus yang melakukan pembelajaran daring pada mata pelajaran penjas. Namun, belum dapat memanfaatkan teknologi, informasi dan komunikasi yang ada, dimana masih sebatas menggunakan 
Pengaruh Penggunaan Google Classroom dan Zoom Meeting dalam Pembelajaran Pendidikan Jasmani Daring

Terhadap Minat Belajar Siswa XI di SMK Wisudha Karya Kudus

Andre Febriansyah Putra Nugraha

Whatsapp dalam proses belajar mengajar secara daring. Oleh karena itu, dalam penelitian ini dilakukan studi kasus mengenai Pengaruh Penggunaan Google Classroom dan Zoom Meeting dalam Pembelajaran Pendidikan Jasmani Daring terhadap Minat Belajar Siswa Kelas XI di SMK Wisudha Karya Kudus.

\section{Pengaruh penggunaan google classroom dalam pembelajaran pendidikan jasmani secara daring}

Google classroom merupakan layanan web gratis yang dikembangkan oleh oleh google untuk sekolah, yang bertujuan untuk menyederhanakan membuat, mendistribusikan, dan menilai tugas dengan cara tanpa kertas. Tujuan utama google classroom adalah untuk merapingkan proses berbagi file antara guru dan siswa.

Dalam penelitian ini, diperoleh hasil uji hipotesis untuk minat belajar siswa kelas XI TITL1 dengan media pembelajaran google classroom diperoleh $\mid$ Thitung $|=|-7,248 \mid>$ Ttabel $(2,032)$ dan Sig. $(0,000)<\alpha(0.05)$,yang berarti terdapat pengaruh penggunaan google classroom dalam pembelajaran pendidikan jasmani daring terhadap minat belajar siswa kelas XI SMK Wisudha Karya Kudus. Dimana terjadi peningkatan rata-rata minat belajar dari pre-test ke post-test yaitu 99,97 naik menjadi 114,23. Sedangkan untuk minat belajar siswa kelas XI TITL2 dengan media pembelajaran google classroom diperoleh nilai $\mid$ Thitung $|=|-3,846 \mid>$ Ttabel $(2,035)$ dan Sig. $(0,001)<\alpha(0.05)$, yang berarti Terdapat pengaruh penggunaan google classroom dalam pembelajaran pendidikan jasmani daring terhadap minat belajar siswa kelas XI SMK Wisudha Karya Kudus. Dimana terjadi peningkatan ratarata minat belajar pre-test ke post-test yaitu 107,03 naik menjadi 113,97.

\section{Pengaruh penggunaan zoom meeting dalam pembelajaran pendidikan jasmani secara daring}

Aplikasi zoom meeting merupakan aplikasi yang memudahkan dalam proses belajar mengajar antara guru dan siswa, dimana kita dapat berkomunikasi langsung dengan siapapun lewat video. Aplikasi tersebut dapat digunakan dalam berbagai perangkat seluler, desktop, hingga telepon dan sistem ruang.

Dalam penelitian ini, diperoleh hasil uji hipotesis untuk minat belajar siswa kelas XI TITL1 dengan media pembelajaran zoom meeting diperoleh nilai $\mid$ Thitung $|=|-2,038 \mid>$ Ttabel $(2,032)$ dan Sig. $(0,049)<\alpha(0.05)$, yang berarti terdapat pengaruh penggunaan zoom meeting dalam pembelajaran pendidikan jasmani daring terhadap minat belajar siswa kelas XI SMK Wisudha Karya Kudus. Dimana terjadi peningkatan rata-rata minat belajar dari pre-test ke post-test yaitu 111,71 naik menjadi 112,86. Sedangkan uji hipotesis untuk minat belajar siswa kelas XI TITL2 dengan media pembelajaran zoom meeting diperoleh nilai $\mid$ Thitung $|=|-2,318 \mid>$ Ttabel $(2,035)$ dan Sig. $(0,027)<\alpha$ (0.05), yang berarti terdapat pengaruh penggunaan zoom meeting dalam pembelajaran pendidikan jasmani daring terhadap minat belajar siswa kelas XI SMK Wisudha Karya Kudus. Dimana terjadi peningkatan rata-rata minat belajar pre-test ke post-test yaitu 111,03 naik menjadi 112,44. 
Setelah dilakukan uji hipotesis untuk siswa kelas XI TITL1 dan kelas XI TITL 2, diperoleh kesimpulan bahwa pemberian media pembelajaran Zoom Meeting berpengaruh secara signifikan terhadap peningkatan minat belajar dalam pembelajaran pendidikan jasmani secara daring pada siswa kelas XI SMK Wisudha Karya Kudus. Penelitian ini dukung olehe penelitian terdahulu yang dilakukan oleh Ni Putu Galuh Kirana Utami (2020) yang mengenai pengaruh pembelajaran daring sinkronus dengan Zoom Meeting berbantuan Kahoot terhadap prestasi belajar Matematika siswa kelas X SMA Negeri 1 Negara.

\section{Perbandingan pengaruh penggunaan google classroom dengan zoom meeting dalam pembelajaran pendidian jasmani secara daring}

Penggunaan media pembelajaran google classroom dan zoom meeting sama-sama berpengaruh terhadap peningkatan minat belajar siswa kelas XI SMK Wisudha Karya Kudus, namun dapat dilakukan perbandingan pengaruh penggunaan google classroom dengan zoom meeting dalam pembelajaran pendidikan jasmani secara daring, untuk menentukan media pembelajaran yang lebih baik dan efektif.

Uji hipotesis pada siswa kelas XI TITL 1 saat diberikan media pembelajaran google classroom dan zoom meeting, diperoleh hasil bahwa nilai Thitung $(2,054)>$ Ttabel $(1,995)$ dan Sig. $(0,044)<\alpha$ $(0,05)$. yang berarti terdapat perbedaan pengaruh penggunaan google classroom dan zoom meeting dalam pembelajaran pendidikan jasmani daring terhadap minat belajar siswa kelas XI SMK Wisudha Karya Kudus. Dimana rata-rata hasil minat belajar siswa kelas XI TITL 1 saat menggunakan media pembelajaran google classroom sebesar 114,23 dan rata-rata hasil minat belajar siswa kelas XI TITL 1 saat menggunakan media pembelajaran zoom meeting sebesar 112,86.

Uji hipotesis pada siswa kelas XI TITL 2 saat diberikan media pembelajaran google classroom dan zoom meeting, diperoleh hasil bahwa nilai Thitung $(2,132)>$ Ttabel $(1,997)$ dan Sig. $(0,037)<\alpha$ (0,05). Maka $\mathrm{H}_{0}$ ditolak dan $\mathrm{H}_{\mathrm{a}}$ diterima yang berarti terdapat perbedaan pengaruh penggunaan google classroom dan zoom meeting dalam pembelajaran pendidikan jasmani daring terhadap minat belajar siswa kelas XI SMK Wisudha Karya Kudus. Dimana rata-rata hasil minat belajar siswa kelas XI TITL 2 saat menggunakan media pembelajaran google classroom sebesar 113,97 dan rata-rata hasil minat belajar siswa kelas XI TITL 2 saat menggunakan media pembelajaran zoom meeting sebesar 112,44.

Karena rata-rata hasil minat belajar saat menggunakan media pembelajaran google classroom lebih tinggi daripada saat menggunakan media pembelajaran zoom meeting dan peningkatan hasil minat belajar saat menggunakan media pembelajaran Google Classroom lebih tinggi daripada Zoom Meeting, maka penerapan media pembelajaran Google Classroom lebih efektif dalam meningkatkan minat belajar siswa dalam pelajaran penjas secara daring di SMK Wisudha Karya Kudus.

Google Classroom dapat memudahkan antara siswa dan guru dalam bertukar file mata pelajaran sehingga setiap saat siswa dapat membuka materi pelajaran di google classroom. 
Pengaruh Penggunaan Google Classroom dan Zoom Meeting dalam Pembelajaran Pendidikan Jasmani Daring

Terhadap Minat Belajar Siswa XI di SMK Wisudha Karya Kudus

Andre Febriansyah Putra Nugraha

\section{KESIMPULAN}

Berdasarkan hasil penelitian dan pembahasan diperoleh kesimpulan sebagai berikut:

Terdapat perbedaan dalam penggunaan media pembelajaran Google Classroom pada pelajaran penjas secara daring dapat meningkatkan minat belajar siswa kelas XI SMK Wisudha Karya Kudus, dimana pada siswa kelas XI TITL 1 setelah diterapkan media pembelajaran google classroom terjadi peningkatan minat belajar sebesar 14,26\%, sedangkan pada siswa kelas XI TITL 2 setelah diterapkan media pembelajaran google classroom terjadi peningkatan minat belajar sebesar $6,49 \%$. Sedangkan penggunaan media pembelajaran Zoom meeting pada pelajaran penjas secara daring dapat meningkatkan minat belajar siswa kelas XI SMK Wisudha Karya Kudus, dimana pada siswa kelas XI TITL 1 setelah diterapkan media pembelajaran zoom meeting terjadi peningkatan minat belajar sebesar $1,02 \%$, sedangkan pada siswa kelas XI TITL 2 setelah diterapkan media pembelajaran zoom meeting terjadi peningkatan minat belajar sebesar $1,27 \%$. Karena peningkatan hasil minat belajar saat menggunakan media pembelajaran Google Classroom lebih tinggi daripada Zoom Meeting. Maka dapat disimpulkan bahwa penerapan media pembelajaran Google Classroom lebih efektif dalam meningkatkan minat belajar siswa dalam pembelajaran pendidikan jasmani secara daring di SMK Wisudha Karya Kudus.

\section{SARAN}

Dari hasil pembahasan dan simpulan di atas, maka dibawah ini beberapa saran yang dapat peneliti sampaikan:

\section{Bagi Guru Penjas SMK Wisudha Karya Kudus}

Bagi guru penjas semoga kedepannya agar lebih baik dan trampil dalam melakukan pembelajaran penjas secara daring selama pandemi Covid-19 agar siswa lebih tertarik dalam mengikuti pembelajaran penjas secara daring.

2. Bagi Sekolah

Agar diberikan bantuan seperti fasilitas atau anggaran untuk pembelian kuota terhadap siswa. Untuk menunjang kegiatan pembelajaran yang dilakukan secara daring selama pandemi Covid-19. 3. Bagi Siswa

Semoga mampu meningkatkan minat belajar siswa dan bermanfaat untuk motivasi belajar siswa dalam pembelajaran penjas daring selama pandemi Covid-19.

\section{DAFTAR PUSTAKA}

Abd. Syakur, Rikhly Faradisy, dan Fajar Surahman. (2020). "Peningkatan Minat Belajar Bahasa Inggris di Akademi Kebidanan Graha Husada Melalui Aplikasi Google Classroom pada Masa Pandemi Covid-19”. Jurnal Pengabdian dan Pemberdayaan Nusantara. 2 (1) 10. 
Abid Azhar, K., \& Iqbal, N. (2018). Effectiveness of Google Classroom: Teachers'Perceptions. Prizren Social Science Journal. 2 (2) 23.

Achmad Paturusi. (2012). Managemen Pendidikan Jasmani dan Olahraga. Jakarta: Rineka Cipta.

Ahmad, Susanto. (2013). Teori Belajar dan Pembelajaran di Sekolah Dasar. Jakarta: Kencana Prenada Media Group.

Allen, Michael. (2013). Michael Allen's Guide to E-learning. Canada: John Wiley \& Sons.

Anisatu Solihah. (2019). Model Dosen dan Mahasiswa dalam Pendalaman Tahsin Tilawah Melalui

Virtual Learning (Studi pada Sekolah Tinggi Shuffah Al Qur'an Abdullah bin Mas'ud Muhajirun Natar Lampung Selatan). Skripsi. Lampung: Fakultas Dakwah dan Ilmu Komunikasi.

Arifin, J. (2017). SPSS 24 untuk Penelitian dan Skripsi. Jakarta: Kelompok Gramedia.

Asep Syamsul M. Romli. (2012). Jurnalistik Online Panduan Mengelola Media Online. Bandung: Nuansa Cendikia.

Barnawi dan Mohammad Arifin. (2014). Kinerja Guru Profesional: Instrumen Pembinaan, Peningkatan dan Penilaian. Jogjakarta: AR-RUZZ MEDIA.

Cahyono, A. (2016). "Pengaruh Media Sosial terhadap Perubahan Sosial Masyarakat di Indonesia". Jurnal ilmu sosial dan ilmu politik. 9 (1) 142.

Danim, Sudarwan. (2010). Profesionalisasi dan Etika Profesi Guru. Bandung: Alfabeta.

Dicicco, K. M. (2016). Rowan Digital Works The Effects of Google Classroom on Teaching Social Studies for Students with Learning Disabilities.

Dini Rosdiani. (2013). Model Pembelajaran Langsung dalam Pendidikan Jasmani dan Kesehatan. Bandung: Alfabeta.

Djamarah, Syaiful Bahri. (2015). Psikologi Belajar. Jakarta: Rineka Cipta.

Dwi Jatmoko. (2013). "Relevansi Kurikulum SMK Kompetensi Keahlian Teknik Kendaraan Ringan Terhadap Kebutuhan Dunia Industri di Kabupaten Sleman”. Jurnal Pendidikan Vokasi. 3 (1) 2 .

Ega Trisna Rahayu. (2018). Pengaruh Inovasi Media Pembelajaran Loud Ball dalam Pendidikan Jasmani terhadap Minat Belajar Siswa Sekolah Menangah Pertama. Skripsi. Karawang: Fakultas Ilmu Keguruan dan Ilmu Pendidikan Universitas Singaperbangsa Karawang

Ernawati. (2018). Pengaruh Penggunaan Aplikasi Google Classroom terhadap Kualitas Pembelajaran dan Hasil Belajar Siswa pada Mata Pelajaran Ekonomi Kelas XI di MAN 1 Kota Tangerang Selatan. Skripsi. Jakarta: Fakultas Ilmu Tarbiyah dan Keguruuan Universitas Islam Negeri Syarif Hidayatullah Jakarta.

Ervinna Anggraini. (2018). Pengaruh Pembelajaran Blended Learning Menggunakan Aplikasi Google Classroom terhadap Pemahaman Konsep Matematika pada Peserta Didik Kelas VIII SMPN 9 Bandar Lampung. Skripsi. Lampung: Fakultas Tarbiyah dan Keguruan Universitas Islam Negeri Raden Intan Lampung. 
Pengaruh Penggunaan Google Classroom dan Zoom Meeting dalam Pembelajaran Pendidikan Jasmani Daring

Terhadap Minat Belajar Siswa XI di SMK Wisudha Karya Kudus

Andre Febriansyah Putra Nugraha

Fathurrohman, M dan Sulistyorini. (2012). Belajar Dan Pembelajaran Meningkatkan Mutu Pembelajaran Sesuai Standar Nasional. Yogyakarta: Teras.

Ghozali, Imam. (2018). Aplikasi Analisis Multivariate dengan Program IBM SPSS 25. Semarang: Badan Penerbit Universitas Diponegoro.

Hamalik, Oemar. (2015). Kurikulum dan Pembelajaran. Jakarta: Bumi Aksara.

Hartanto, W. (2016). "Penggunaan E-Learning Sebagai Media Pembelajaran”. Jurnal Pendidikan Ekonomi. 10 (1) 7-9.

Hartinah, Siti. (2010). Perkembangan Peserta Didik. Bandung: PT. Rafika Aditama.

Haqien, Danin \& Rahman Afiifadiyah, A. (2020). "Pemanfaatan Zoom Meeting untu Proses pembelajaran pada Masa Pandemi Covid-19”. Jurnal Pendidikan. 5 (1) 52.

Hidayati, N. (2010). "Sistem E-Learning untuk Meningkatkan Proses Belajar Mengajar: Studi Kasus pada SMA Negeri 10 Bandar Lampung”. Jurnal Telematika MKOM. 2 (2) 155-156.

Isjoni. (2011). Cooperative Learning Mengembangkan Kemampuan Belajar Berkelompok. Bandung: Alfabeta.

Karwati, Eui dan Donni Juni Priansa. (2014). Manajemen Kelas. Bandung: Alfabeta.

Makmun Khairani, 2017.Psikologi Belajar. Yogyakarta: PT Aswaja Pressindo.

Masganti. (2012). Perkembangan Peserta didik. Medan: Perdana Publishing.

Mulyanto, R. (2014). Belajar dan Pembelajaran Penjas. Bandung: UPI.

Nawawi. (2015). Manajemen Sumber Daya Manusia. Yogyakarta: Universitas Gadjah Mada.

Ni Putu Galuh Kirana Utami. (2020). Pengaruh Pembelajaran Daring Sinkronus dengan Zoom Meeting Berbantuan Kahoot terhadap Prestasi Belajar Matematika Siswa Kelas X SMA NEGERI 1 Negara. Skripsi. Singaraja: Fakultas Matematika dan Ilmu Pengetahuan Alam Universitas Pendidikan Ganesha Singaraja. 